South African Journal of Geomatics, Vol. 6. No. 3, October 2017

\title{
Introducing an agricultural land capability framework for land reform beneficiaries
}

\author{
T.H Kabanda \\ Geography, Sol Plaatje University, Private Bag X5008, Kimberley, 8300 \\ Email: tabaro.kabanda@spu.ac.za
}

DOI: http://dx.doi.org/10.4314/sajg.v6i3.2

\begin{abstract}
This study incorporated remote sensing, geographic information system (GIS), and geostatistics to assess land capability in two sites acquired through land reform program. The relationships and interactions between components and parameters that are necessary for analysing the capability of agricultural land were investigated for an effective management system. The parameters taken into consideration were biophysical environment (soil texture, organic matter content, soil depth etc.), socio-economic and policy. The primary data included climatic data and soil samples obtained at 1 $m$ depth; the secondary data included satellite imagery, topographic map, and agricultural statistics. The resulting land capability maps showed that the study areas have moderate to very high capability for summer crops. It is concluded that in order for land reform to contribute to sustainable livelihoods for land reform beneficiaries, agricultural land capability study should be integrated in land reform policy before issuing land to land reform beneficiaries.
\end{abstract}

Keywords: land reform, land capability, remote sensing, GIS

\section{Introduction}

Availability of land and its productive resources is generally very important for rural poor to improve their living conditions and lessen poverty. Land reform is the redistribution of property or rights in land for the benefit of the landless, tenants and farm labourers (Warriner, 1969). In modern times, land form has been defined as a manmade change to land tenure usually aimed at changing land distribution (Anaafo, 2015; Torhonen, 2004). Post 1994 South Africa, land reform has played an important part of the rebuilding and growth plan of the new African National Congress (ANC) administration. The South African land reform policy intends to mainly address the ethnically slanted land ownership, which sprang from the 1913 Land Act and consequent legislation, decreasing poverty and contributing to economic growth, particularly in areas that were marginalised through apartheid laws, and securing land and tenure rights of the marginalised people (DLA, 1997).

The land reform program thus intends to attain goals of both equity (in terms of land access and possession) and productivity (greater land use), while also contributing to the expansion of the rural economy in the country. In terms of overall achievements, land reform in South Africa consistently has fallen far behind the targets set by the state, and behind popular expectations (Binswanger- 
Mkhize et al., 2009). Land tenure targets were to blame for the country's failed land reform programme, and $25 \%$ of the national department of agriculture's budget in 2012 was spent on recapitalising 595 claimed farms (Farmers weekly, 2012). According to the national Minister for Agriculture, Gugile Nkwinti, this amounted to R900 million that went into rehabilitating collapsed farms handed to claimants since 1994 (Dardagan, 2012).

This research aims to assess the land capability of redistributed land for arable agriculture and to suggest the implementation of land capability study as part of land reform policy prior to acquisition of land. The study sites are the former Pienaars Nature Reserve near Zeerust and the Antwerp farm near Matloding. The agricultural potential is evaluated using an agricultural land capability framework and this research intends to recommend the outcomes to land reform policy makers as identification of very suitable and promising crop growing areas might be made distinct from unsuitable land use type or land degradation. It is also very important that the result of agricultural land capability evaluation is brought into the reach of farmers. In some cases, (Lahiff and $\mathrm{Li}, 2012$ ), there is a prerequisite that new beneficiary's/land owner's exhibit profitability inside the given three to five years and this is generally impractical for a farming start-up without adequate knowledge of the land.

Agricultural land capability framework in this study incorporates land quality information (e.g. land forms and soils) and socio-economic factors. The information is then integrated in a geographic information system (GIS) to produce thematic layers for use in land capability evaluation. Since land capability analysis requires the use of different kinds of spatial data and information, the GIS offers a more flexible and powerful tool than conventional data processing systems, as it provides a means of taking large volumes of different kinds of spatial data sets, and manipulating and combining the data sets into new data sets which can be displayed in the form of thematic maps (Al-Mashreki et al, 2011). Remote-sensing plays an increasingly significant role in providing current and historical land-use data, and for environmental and natural resources mapping. This is because remote sensing data provides repeated synoptic coverage with consistent observation of a given site. Land capability evaluation is the estimation of land quality for a specific use. This study thus makes use of GIS, geostatistics and remote sensing to develop an agricultural land capability framework for land reform beneficiaries. According to FAO (2007), a framework does not by itself constitute an evaluation system. Instead, it sets out a number of concepts involved in land evaluation, some basic concepts, the structure of a capability classification and the procedures necessary to carry out a land capability evaluation. 


\section{Materials and Methods}

\subsection{Description of the study area}

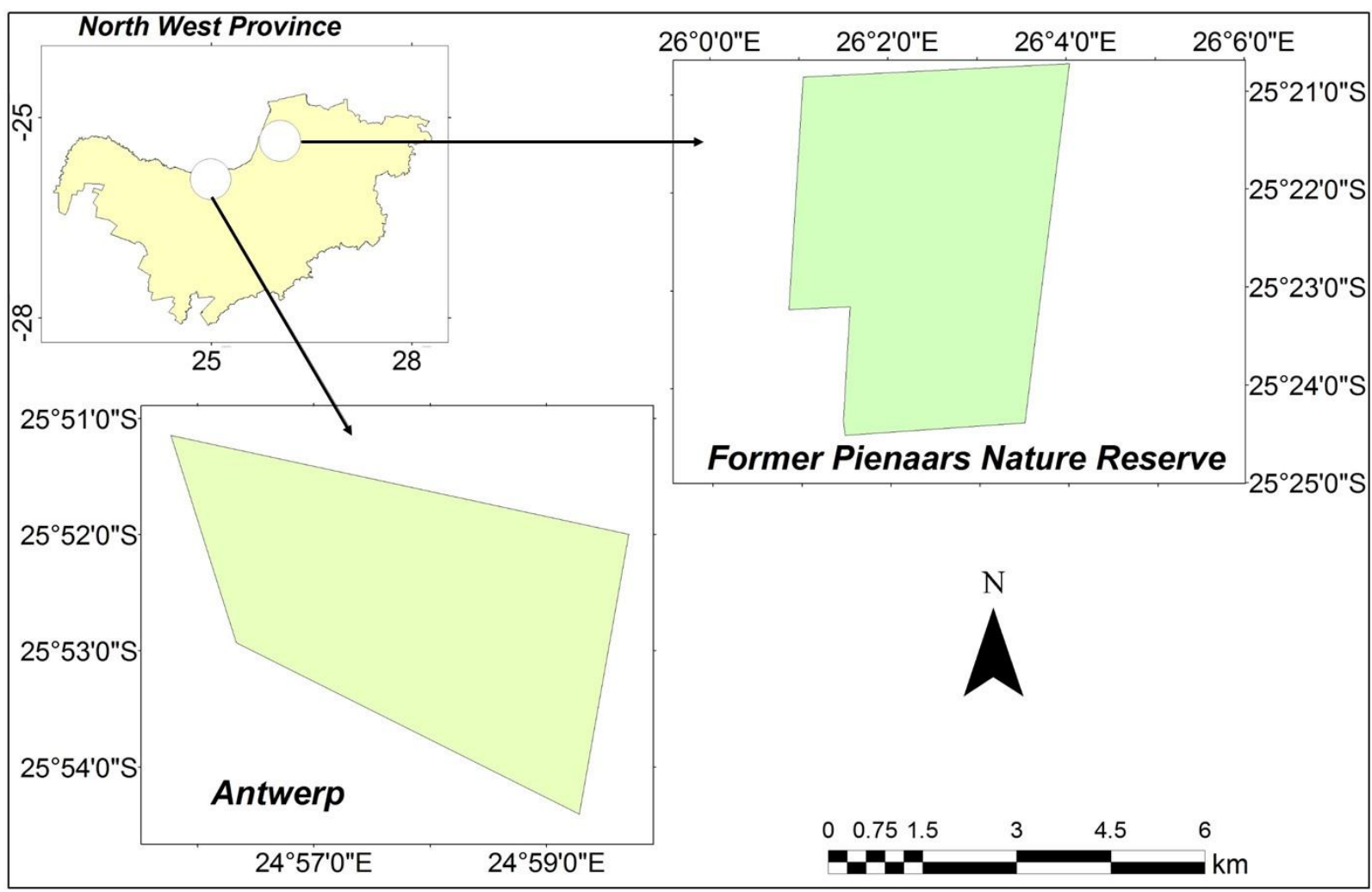

Figure 1: Map of FPNR and Antwerp farm in North West Province

Figure 1 shows a map of the former Pienaars Nature Reserve (FPNR) near Zeerust and the Antwerp farm near Matloding. The study sites are characterised by summer rainfalls with very dry winters. Semi-arid conditions prevail in the study sites with an average annual rainfall of $300 \mathrm{~mm}$ in Matloding and $500 \mathrm{~mm}$ in Zeerust. Great seasonal and daily variations in temperature occurs with summers being very hot, with daily average high of $36{ }^{\circ} \mathrm{C}$ in January and winters cold with an average daily minimum of $0,9^{\circ} \mathrm{C}$ in June (READ, 2015).

\subsection{Preparation of an agricultural land capability framework}

Well-structured agricultural land capability framework is necessary to deliver informed decisions on land use. The framework (Figure 2) is an in-built component of a GIS and has a tremendous impact on the output. GIS allows for easier interaction of spatial and non-spatial data (Dale and McLaren, 2005). Incorporating data from a variety of fields such as physical, social and economic of a region in a capability study allows for better results. 


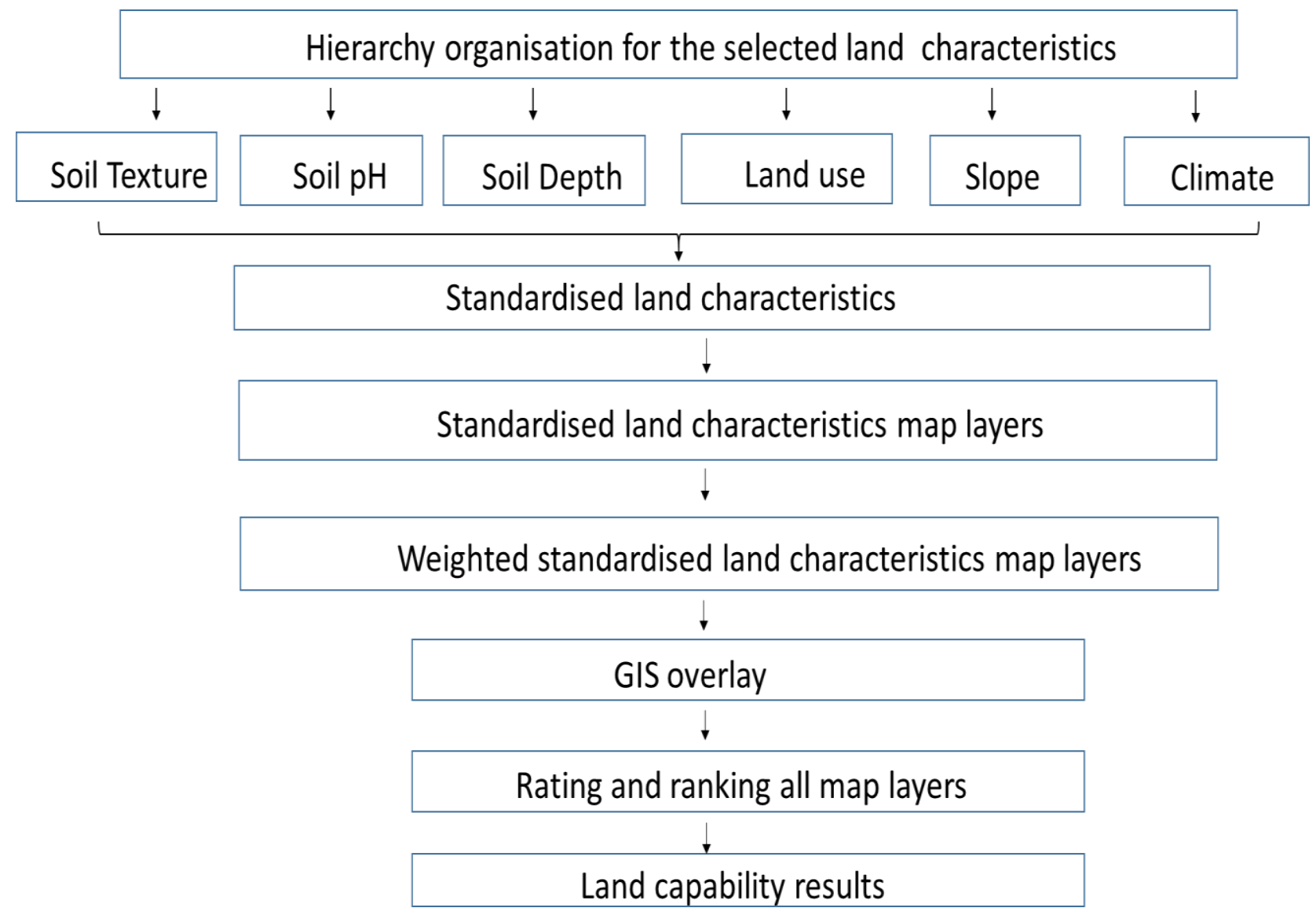

Figure 2: Methodological approach

The framework allows for the development of the land information database necessary to provide sufficient and accurate information on land and soil features which are then converted into thematic maps in a GIS. The thematic layers (such as soil depth, soil texture and topography) are to be overlaid using the weight analysis to produce an agricultural land capability map for a study area.

\subsection{Remote sensing application}

SPOT 5 HRG satellite images for the two study sites were acquired from the South African National Space Agency (SANSA). The images have a spatial resolution of $10 \mathrm{~m}$ in bands 1 (green, $0,50-0,59 \mu \mathrm{m}$ ), 2 (red, 0,61-0,68 $\mu \mathrm{m}$ ), and 3 (near-infrared, 0,78-0,89 $\mu \mathrm{m}$ ), and a spatial resolution of $20 \mathrm{~m}$ in band 4 (mid-infrared, $1,58-1,75 \mu \mathrm{m}$ ). The image covers an area approximately $60 \mathrm{~km} \times 60 \mathrm{~km}$ and was taken in the rainy season. The rainy season was chosen as leaf chlorophyll is high and this is suitable for calculation of NDVI values. Geometric distortions in the satellite imagery were removed by registering the image to a map by using ground control points (GCP). Sets of coordinates linked with each GCP are spread uniformly over the image to give best coverage for calculating the transformation. Hybrid classification which combines the benefits of both supervised classification and unsupervised classification was performed. The classification gave rise to 2 land cover classes comprising of water, woodland and bare land. Google Earth imagery and field data were used as reference data to evaluate the correctness of the 
classification process. An error matrix was used to evaluate the accuracy of image classification and can also be used to refine the classification (Lu and Weng, 2007).

Table 1: Former Pienaars Nature Reserve error matrix

\begin{tabular}{|c|c|c|c|c|c|}
\hline & & \multicolumn{3}{|c|}{ REFERENCE DATA } & \multirow[b]{2}{*}{ User accuracy (\%) } \\
\hline & & B & $\mathbf{O}^{\mathbf{W}}$ & al & \\
\hline & $\mathbf{B}$ & 28 & 4 & 32 & 87.50 \\
\hline & WO & 14 & 214 & 228 & 93.86 \\
\hline & Total & 42 & 218 & 260 & \\
\hline $\begin{array}{l}\text { Producer accuracy } \\
(\%)\end{array}$ & & 66.67 & $17^{98 .}$ & & Overall accuracy $=93.08 \%$ \\
\hline
\end{tabular}

Legend: WO-Woodland, B-Bare land,

The ERDAS Imagine Accuracy Assessment tool was used to select stratified random reference points; a minimum of fifty points were selected in each of the three land cover categories of interest. According to Congalton (1991), a total of 250 reference pixels or more are required to approximate the mean accuracy of a class to within plus or minus $5 \%$. 
Table 2: Error matrix for the classification of the Antwerp (2013-02-11)

\begin{tabular}{|c|c|c|c|c|c|}
\hline & & REFE & RENCE D & & \\
\hline & & WO & B & Total & User accuracy (\%) \\
\hline & WO & 176 & 21 & 197 & 87.83 \\
\hline & B & 8 & 55 & 63 & 87.30 \\
\hline & al Tot & 184 & 76 & 260 & \\
\hline $\begin{array}{l}\text { Producer accuracy } \\
(\%)\end{array}$ & & 94.86 & $7^{72.3}$ & & Overall accuracy $=87.56 \%$ \\
\hline
\end{tabular}

Legend: WO - Woodland, B - Bare land

The FPNR had an accuracy of 93,08\% and the overall kappa statistic of 0,7173 (Table 1) and for Antwerp farm the accuracy was $87,56 \%$ (Table 2) and the overall kappa statistic, $\kappa$, was 0,7195 . The kappa statistic calculates inter-rater agreement for qualitative objects (McHugh, 2012).

\subsection{Soil sampling and geostatistical analysis}

Soil sampling in this study was done during the late summer (March and May of 2014) as the best time to collect soil samples for fall-seeded crops (e.g. cereals and grains) is when the field is idle, and in the summer works well (FAO, 2007). A total of 30 sampling sites (15 per site) were collected at $100 \mathrm{~cm}$ depth using auger bores. For interpolation and to show spatial association in observations measured at sampled sites, a semivariogram was used, as follows (Kerry et al., 2010):

$$
\Upsilon(\mathrm{h})=\frac{1}{2 N(h)} \sum_{i=1}^{N(h)}\left[z\left(x_{i}\right)-z\left(x_{i}+h\right)\right]^{2}
$$

Where $\gamma$ is the semivariogram value plotted on the dependent axis, $N(\mathrm{~h})$ is the number of data pairs within the class of distance and direction used for the lag vector $\mathrm{h}, x_{i}$ is the starting location and $x_{i}+h$ is the ending location, also the variable $z$ is isotropic.

Physical and chemical parameters were analysed from the soil samples. Soil texture was determined using sieve analysis, in sieve analysis the sieves are arranged by the size of the aperture in $\mathrm{mm}$. The purpose of a sieve analysis is to determine the amount of clay, silt, and sand particles in a given soil. Grahm colorimetric method was used to measure organic matter in the soil. The method comprised adding a soil sample in a flask to a potassium dichromate solution where it was swirled and allowed to stand for 30 minutes for settling of soil particles. A pipet was used to add 10 drops of diphenylamine indicator and swirled until the colour changed from dark brown through blue to a deep green; the colour was matched with organic matter endpoint colour standard. Soil $\mathrm{pH}$ 
was calculated using the potentiometric method and soil suspension was done with purified water in 1:1 ratio. The $\mathrm{pH}$ was then measured using a Lamotte $1741 \mathrm{pH}$ Tracer meter.

\subsection{Selection of promising crops}

Promising crops were selected based on existing cropping systems, social acceptance of crops and economic status of the society, and from farmers' long experience. Summer field crops are well suitable for the North West Province climatic conditions. Information on the growth requirements for maize and sorghum were acquired from farmers and literature (DAFF, 2010). The information resulted in the construction of climatic and soil requirements tables (Table 3).

Table 3: Diagnostic characteristics for sorghum

\begin{tabular}{|l|l|l|l|}
\hline Characteristics & Capable & Moderate & Incapable \\
\hline Texture & Clay & Loam & Sandy \\
\hline $\mathrm{pH}$ & $5,5-7,5$ & $7,5-8,5$ & $<4,5$ \\
\hline Drainage & Well drained & Moderately well & Imperfectly drained \\
\hline Clay $(\%)$ & $10 \%-20$ & $10 \%-30$ & $>30$ \\
\hline Depth $(\mathrm{cm})$ & $>100$ & $80-100$ & $<80$ \\
\hline Temp $\left({ }^{\circ} \mathrm{C}\right)$ & $27-30$ & $7-10$ & $<7$ \\
\hline Rainfall $(\mathrm{mm})$ & $300-750$ & $200-300$ & $<200$ \\
\hline
\end{tabular}

\subsection{Land capability assessment}

The Spatial Analyst function in ArcGIS was used to generate thematic maps of textural class, soil depth, drainage condition and clay percentage. The thematic maps were then overlaid to create a land capability map. The land capability classes were defined using the rating method after FAO (2007). Each one of the classes of thematic layers for texture class, soil depth, pH and clay percentage was categorised into (i) good, (ii) fair, (iii) moderate, (iv) average, (v) poor and (vi) not capable with respect to land capability for agricultural purposes. Capability weights were given to each thematic layer after considering their characteristics.

The weighted aggregation technique in ArcGIS was used to carry out the weighting for each thematic layer. This technique works by combining multiple layers and applying a common measurement scale of values to each layer, weighting each according to its importance, and adding them together to create an integrated analysis. Input factors favouring agriculture were changed from descriptive form into agricultural land capability ratings to allow for the calculation and other 
mathematical processes in GIS analysis. Also because these factors have different value scales and not all of them are equally important.

\section{Results}

\subsection{Land use structure}

The former Pienaars Nature Reserve (FPNR) covers an area of $29,8 \mathrm{~km}^{2}$; the landscape is dominated by vegetation cover $(92,7 \%)$ whilst bare land makes up 7,4\%. The FPNR remains largely uninhabited, and a 2011 census recorded just three households, although surrounding communities do graze their livestock within FPNR (STATSA, 2012). Antwerp farm consists of 88,4\% of woodland and $11,6 \%$ is bare land (Figure 3 ).

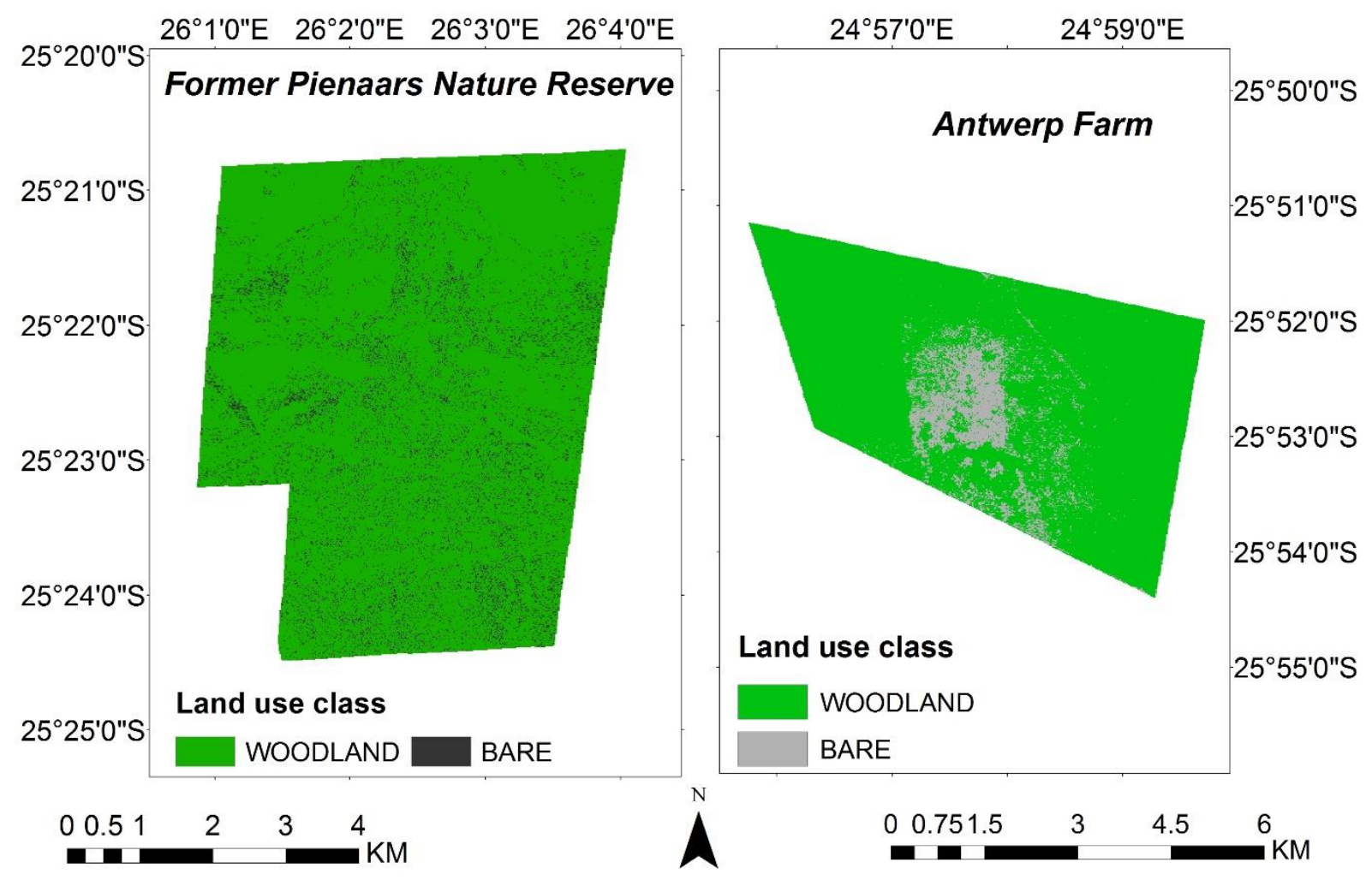

Figure 3: Land use classes of FPNR and Antwerp farm

\subsection{Physical properties}

Figure 4 shows Clay loam accounts for $11,75 \%$ of FPNR while sandy loam covers $67,33 \%$ and clay (light) at $20,92 \%$. Clay loam soils are heavy as the soil mixture contains more clay than other types. Clay loam has imperfect drainage and this can stunt plant growth due to the characteristic of swelling of the soil to retain water when it is very wet and cracking during very dry conditions. These drawbacks can be lessened by adding organic matter over time (Chesworth, 2008). Figure 4 shows that sandy soil texture covers the entire Antwerp farm.

Moderately well drained soil covers $88,25 \%$ of FPNR and in moderately well drained soil, water is removed from the soil at a lower rate and thus the soil is wet for longer periods. Periodically, the soil can be wet enough that mesophytic crops (examples are maize and many fruit trees and 
vegetables) are affected as wetness markedly restricts the growth of mesophytic crops, unless artificial drainage is provided (Belt et al., 2007). Sand texture class in Antwerp farm has a somewhat excessive drainage class i.e. water is rapidly lost.

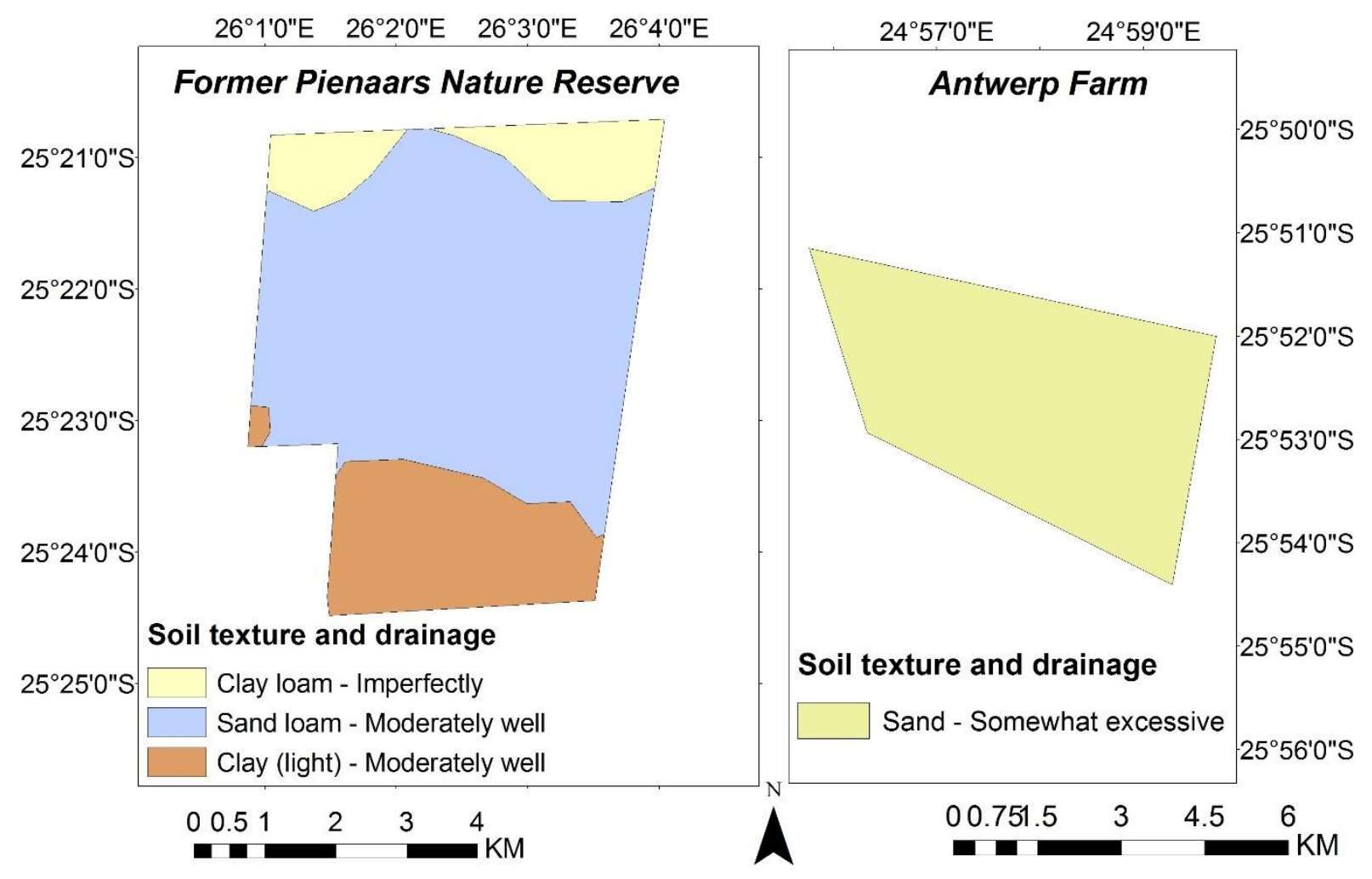

Figure 4: Soil texture and drainage of FPNR and Antwerp farm

\subsection{Chemical properties}

The effect of soil $\mathrm{pH}$ is great on the solubility of minerals or nutrients. The $\mathrm{pH}$ range of 7.1 to 7.5 in FPNR is due to Ferric Luvisols soils, these have high cation exchange capacity (Chesworth, 2008). Cation exchange capacity (CEC) is dependent on soil $\mathrm{pH}$, thus a high CEC means the soil is acidic as more cations are available.

\section{Discussion}

\subsection{Maize cultivation land capability evaluation}

The FPNR is highly capable for cultivation of maize, with $83 \%$ being highly and moderately capable. This area consists of clay (light) and sandy loam soil texture. Maize production generally takes place on soils with clay content of less than $10 \%$ (sandy soils) or in excess of $30 \%$ (clay and clay-loam soils) (DAFF (b), 2010). Marginal capable soil covers 17\% of the FPNR and the presence of clay loam prevents good internal drainage and optimal moisture regime. The sandy soils of Antwerp farm are capable for maize cultivation as it provides good internal drainage and an optimal moisture regime. The crop needs to be highly irrigated during the dry periods as the soil needs to be able to retain few weeks of water or the crop suffers. With a soil depth of $100 \mathrm{~cm}$, it is free from 
restrictive layers (hardpan) and has a $\mathrm{pH}$ of higher than 4.5. Figure 5 shows the land capability classified map for maize in the FPNR.

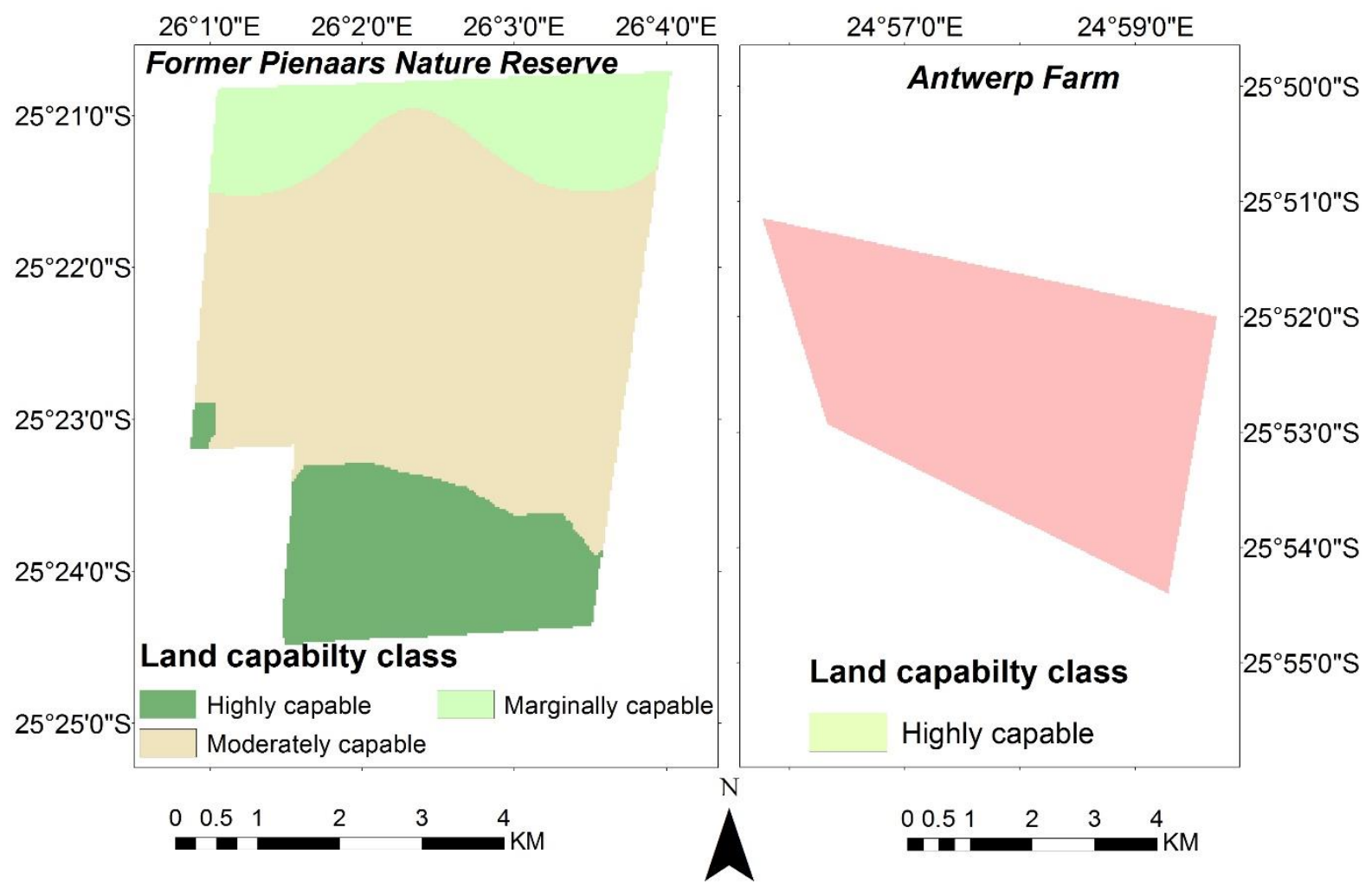

Figure 5: Land capability classified map for maize in the FPNR and Antwerp farm

\subsection{Sorghum cultivation land capability evaluation}

Grain sorghum can be grown on many different soils and the presence of shallow soil depth and clay loam texture means that only $15 \%$ of FPNR is highly capable for sorghum. Moderately capable area covers $74 \%$ of FPNR and consists both of sandy loam and clay (light) soil.

The marginal capability in FPNR covers $11 \%$. This area has a pH range from 6.0 to 6.6 (Figure 6). Sorghum usually grows poorly on sandy soils and with Antwerp farm covered by sandy soil texture, the area is marginally capable for cultivation. All other factors such as $\mathrm{pH}$ of 6.1, a soil depth of $100 \mathrm{~cm}$ and a deep well-drained fertile soil are appropriate. Figure 7 shows the land capability classified map for sorghum in FPNR and Antwerp farm. 


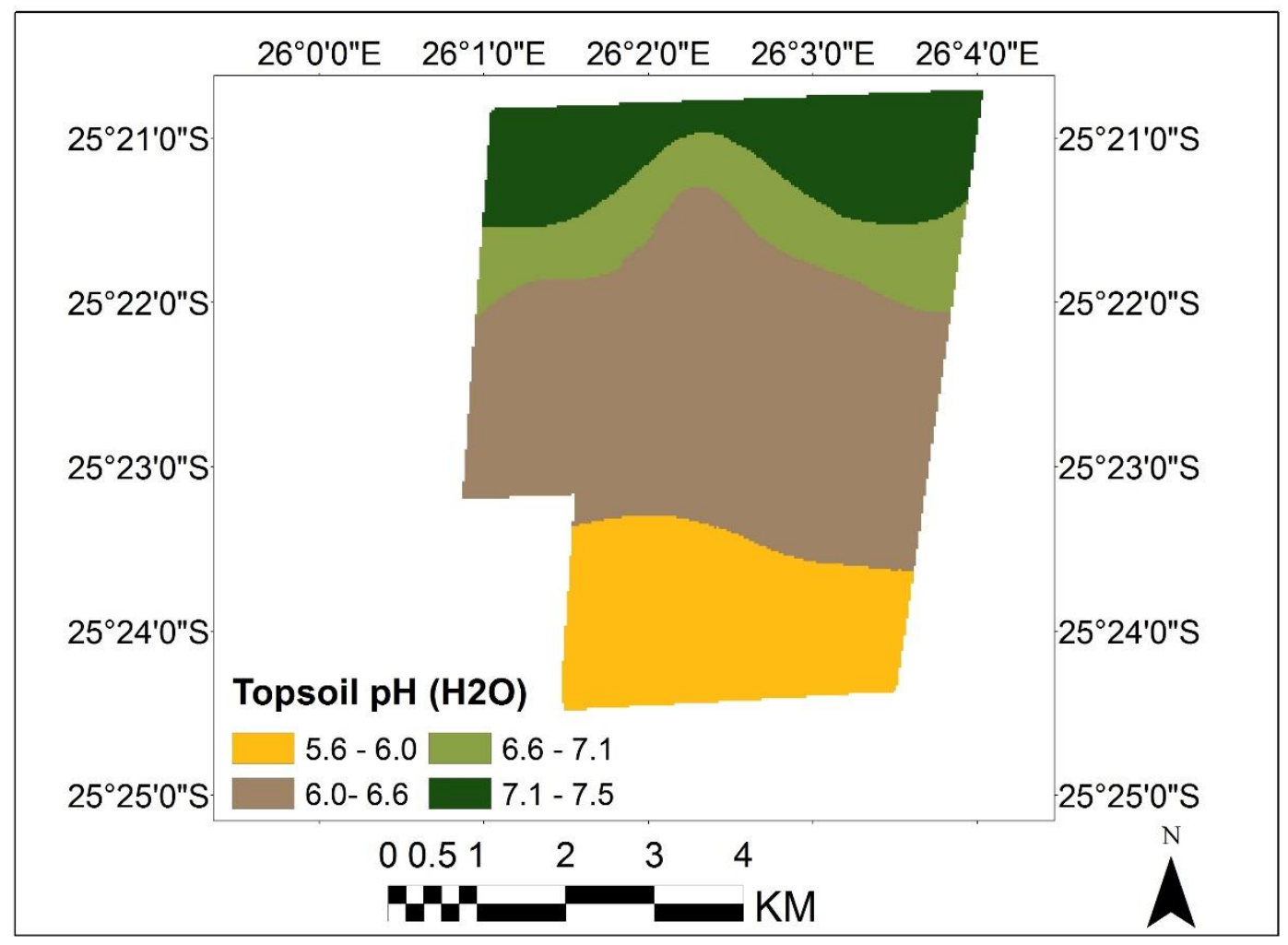

Figure 6: Soil pH in FPNR

\section{Conclusion}

Soil depth is generally not a problem as only $13 \%$ of the study areas are below $100 \mathrm{~cm}$. Data analysis showed that only $21 \%$ of drainage was imperfect, and all crops (maize and sorghum) had almost ideal drainage conditions. Sorghum, though, can better tolerate short periods of waterlogging compared to maize. $22 \%$ of the study areas had the high clay content ideal for sorghum. The soils in the sites largely do not suffer from fertility deficiency. The study sites also have favourable climatic conditions as they receive an average of $500 \mathrm{~mm}$ of annual rainfall and temperature ranges from 27 to $36^{\circ} \mathrm{C}$. 


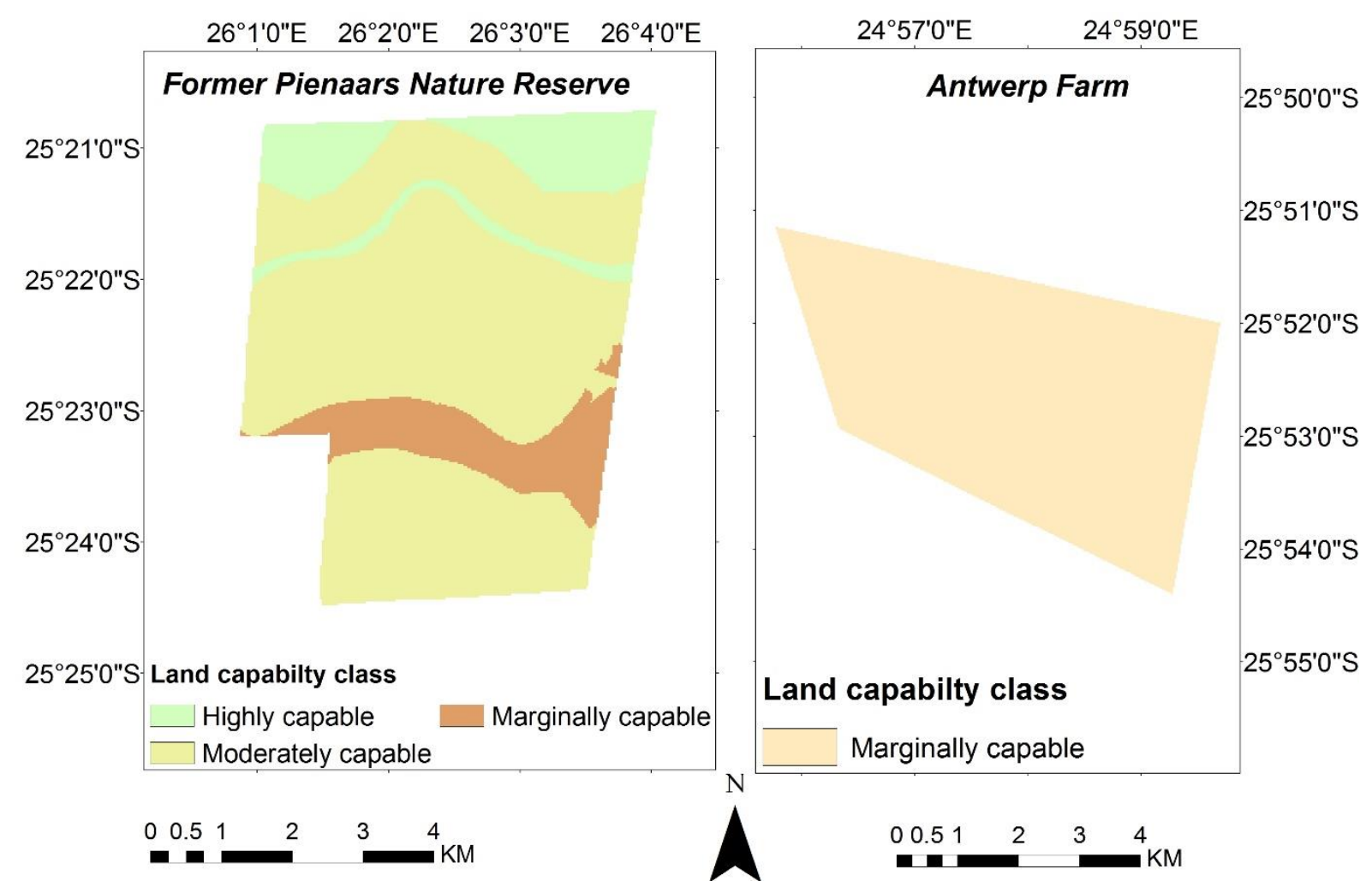

Figure 7: Land capability classified map for sorghum in the FPNR and Antwerp farm

A large part of this study was tied to the development of a framework intended to determine agricultural land capability. There is generally no comprehensive policy that is intended to provide support for agricultural development to land claimants after land transfer. Land capability evaluation should form part of post-settlement assistance to beneficiaries as they and the authorities will have information on the relative capability for agriculture on their land. Also, the risk of land degradation and the necessity to manage land within its capability should be acknowledged at the state level. The more that land is used within its capability, the more sustainable will be the land management practices. This study therefore proposes the application of land capability study as part of land reform policy preceding the acquirement of land to land beneficiaries and also as part of post-transfer support.

\section{References}

Al-Mashreki, MH., Akhir, JBM., Rahim, SA., Desa, KM., Lihan, T \& Haider, AR 2011, 'Land suitability evaluation for sorghum crop in the Ibb Governorate, Republic of Yemen using remote sensing and GIS techniques', Australian journal of basic and applied sciences, vol. 5, pp 359-368.

Anaafo, D 2015, 'Land reforms and land rights change: A case study of land stressed groups in the Nkoranza South Municipality, Ghana', Land Use Policy, vol 42, pp 538-546.

Belt, SV., van der Grinten, M., Malone, G., Patterson, P \& Shockey, R 2007, 'Windbreak Plant Species for Odour Management around Poultry Production Facilities', Maryland Plant Materials Technical Note No. 1. USDA-NRCS National Plant Materials Center, Beltsville, MD. 21p. 
Binswanger-Mkhize, H.P, Bourguignon, C \& Brink, R 2009, 'Agricultural Land Redistribution: Toward Greater Consensus', International Bank for Reconstruction and Development / The World Bank. $1818 \mathrm{H}$ Street NW, Washington DC 20433.

Baniya, N 2008, 'Land suitability evaluation using GIS for vegetable crops in Kathmandu valley, Nepal' Ph.D. thesis submitted to Humboldt University of Berlin.

Chesworth, W 2008, 'Encyclopaedia of Soil Science (Encyclopaedia of Earth Sciences)', Springer 2008, XXVI, $902 \mathrm{p}$.

DAFF 2010, 'Maize - Production guideline', Directorate Plant Production, Private Bag X250, Pretoria 0001. ARC-Grain Crops Institute, Pretoria, South Africa.

DAFF 2013, 'Strategic plan 2011/12 to 2014/15', Directorate Agricultural Information Services Private Bag X144, Pretoria 0001.

Dale, PF \& McLaren, RA 2005, 'GIS in land administration'. In: Harlow \& Longman, eds. Geographical Information Systems: Principles, Techniques, Management and Applications, Abridged Edition ed. New York: John Wiley \& Sons, Inc., pp. 859-875.

Dardagan, C 2012, 'Land reform a failure'. Accessed 2015-12-03, Available: http://www.plaas.org.za/newscategories/land-reform?page $=58$

DLA (Department of Land Affairs) 1997, 'White Paper on South African Land Policy', Pretoria: DLA.

FAO 2007, 'The state of food and agriculture 2007'. FAO, Viale delle Terme di Caracalla, 00100 Rome, Italy.

Farmers weekly 2012, 'Land reform a failure, says minister'. Accessed 2015-11-13, Available: http://alibuye.co.za/?p=165.

Kerry, R., Oliver, MA \& Frogbrook, ZL 2010. 'Geostatistical applications for precision agriculture', International Journal of Applied Earth Observation and Geoinformation, Vol 5, pp 55-64.

Lahiff, E \& Li, G 2012. 'Land redistribution in South Africa: A critical review'. Agricultural Land Redistribution and Land Administration in Sub-Saharan Africa, 27.

Lu, D \& Weng, Q 2007. 'A survey of image classification methods and techniques for improving classification performance', International Journal of Remote Sensing, vol. 28(5), pp 823-870.

McHugh, M 2012, 'Interrater reliability: the kappa statistic', Biochemia Medica, vol. 22(3): pp 276-282.

READ. 2015, 'Climate Change Vulnerability: North West Province'. Climate Support Programme (CSP). Pegasys Strategy and Development (Pty) Ltd

STATSSA (Statistics South Africa), 2012, 'Census 2011 Statistical release', Statistics South Africa, Private Bag X44, Pretoria 0001. Available: www.statssa.gov.za.

Törhönen, M 2004, 'Sustainable land tenure and land registration in developing countries, including a historical comparison with industrialised country'. Computers, Environment and Urban Systems, vol. 28(5), 545-586.

Warriner, D 1969, 'Land reform in principle and practice', Clarendon Press: Oxford. ISSN: 1356-9228. 